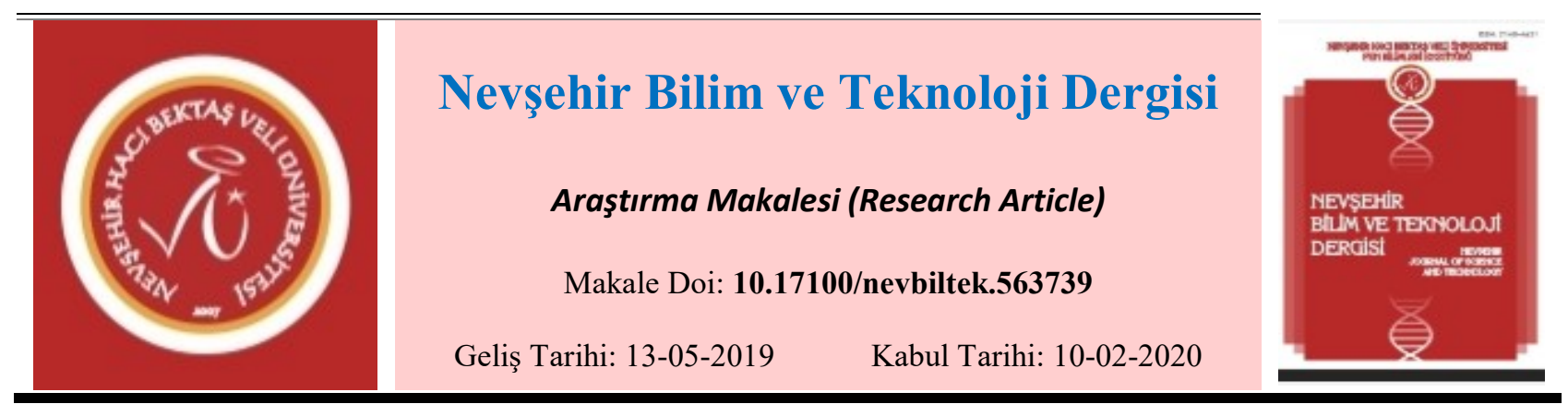

\title{
Batı Akdeniz Bölgesi Crataegus L. Taksonlarının Bazı Morfolojik ve Biyokimyasal
}

\section{Özellikleri $^{1}$}

\author{
Nurtaç ÇINAR $^{1 *}$, Fatma UYSAL BAYER ${ }^{2}$, Fırat AYAS ${ }^{3}$, Arzu BAYIR YEĞİN ${ }^{4}$, Mehmet ÖTEN $^{5}$ \\ ${ }^{1}$ Batı Akdeniz Tarımsal Araştırma Enstitüsü, Antalya/ Türkiye \\ ORCID ID:0000-0001-6093-3177 \\ ${ }^{2}$ Batı Akdeniz Tarımsal Araştırma Enstitüsü, Antalya/ Türkiye \\ ORCID ID:0000-0002-7130-5704 \\ ${ }^{3}$ Yüreğir İlçe Tarım ve Orman Müdürlüğü, Adana/ Türkiye \\ ORCID ID:0000-0001-8426-3171 \\ ${ }^{4}$ Batı Akdeniz Tarımsal Araştırma Enstitüsü, Antalya/ Türkiye \\ ORCID ID:0000-0002-2194-6730 \\ ${ }^{5}$ Batı Akdeniz Tarımsal Araştırma Enstitüsü, Antalya/ Türkiye \\ ORCID ID:
}

Öz

Yaygın olarak 'alıçlar' ismiyle bilinen Crataegus L. cinsi, Rosaceae Juss. familyasının bir üyesi olup, yaprak döken dikenli ağaç ve çalılardan oluşmaktadır. Cinse ait türler meyve ağacı, peyzaj bitkisi ve tıbbi bitki olarak değerlendirilmektedir. Bu çalışmada Antalya, Isparta ve Burdur illerinde doğal yayılış gösteren Crataegus taksonlarının genel dağılımı, bazı morfolojik ve biyokimyasal özelikleri incelenmiştir. Morfolojik özellikler olarak; çiçek çapı (mm) ve kümedeki sayısı (adet),yaprak eni (mm), boyu (mm) ve rengi (L, a, b, c, Hº), meyvede tohum sayısı (adet) ve tohum ağırlı̆̆ (g), meyve eni (mm), boyu (mm), rengi (L, a, b, c, Hº), ağırlı̆̆ı (g) belirlenmiştir. Biyokimyasal özellikler olarak ise suda çözünen kuru madde (SÇKM \%), pH, toplam asitlik (\%), nem (\%) ve kül (\%) değerleri belirlenmiştir. Bölgede doğada bolluk bakımından C. monogyna var. monogyna Jacq ve C. orentalis Pall. Ex M. Bieb. subsp. orientalis(Sarı meyveli), gençleşme bakımından ise C. azarolus L. taksonları ön plana çıkmıştır. Ölçüm ve analizlerde taksonlar/ genotipler bazında değişen sonuçlar alınmıştır ve veriler bölgede cins üzerine yapılacak çalışmalar için temel oluşturacaktır. Tanımlanan Crataegus taksonlarının farklı alanlarda değerlendirilmesi ve sürdürülebilir şekilde korunması gerektiği düşünülmektedir.

Anahtar Kelimeler: Crataegus; Alıç; Batı Akdeniz; Morfoloji; Biyokimyasal özellikler

\section{Some Morphological and Biochemical Properties of Crataegus L. Taxa of Western Mediterranean Region}

Abstract

Crataegus is a member of Rosaceae family. They are deciduous trees or shrubs usually with thorns. The taxa of the genus are used for medical purposes, fruit tree and landscaping. In this study, were determined Crataegus taxa, which are naturally distributed in the Isparta, Burdur and Antalya provinces, and also were determined that general distribution properties, some morphological and biochemical properties. Morphological features; flower diameter

\footnotetext{
${ }^{1}$ Bu araştırmaTarımsal Araştırmalar ve Politikalar Genel Müdürlüğü tarafından TAGEM/TBAD/12/A01/P01/007nolu proje ile desteklenmiştir ve bir bölümü 8-10 Nisan 2019 tarihinde düzenlenen 'International Congress on Agriculture and Forestry Research' (AGRIFOR) Kongresi’nde sözlü sunu olarak sunulmuştur.

*Sorumlu yazar e-mail: nurtac.cinar@tarimorman.gov.tr
} 
$(\mathrm{mm})$ and number in the cluster (pcs), leaf width (mm), length (mm) and color (L, a, b, c, $\left.\mathrm{H}^{\circ}\right)$, number of seeds in fruit (pcs) and seed weight (g), fruit width $(\mathrm{mm})$, length $(\mathrm{mm})$, color $\left(\mathrm{L}, \mathrm{a}, \mathrm{b}, \mathrm{c}, \mathrm{H}^{\circ}\right)$, weight $(\mathrm{g})$ were determined. Biochemical properties; water soluble dry matter $(\%)$, pH, total acidity (\%), moisture (\%) and ash (\%) were determined. C. monogyna var. monogyna Jacq and C. orentalis subsp. orientalis Pall. Ex M. Bieb. (Yellow fruit) in abundance in nature and C. azarolus taxa in terms of rejuvenation were prominent. Changing results were taken on the basis of taxa/ genotypes in the measurements and analysis. The data obtained will form the basis to be held studies for the genus in region. It is thought that the defined Crataegus taxa should be evaluated in different areas and protected in a sustainable way.

Keywords: Crataegus; Hawthorn; Western Mediterranean; Morphology; Biochemical properties

\section{Giriş}

Yaygın olarak 'alıç' ismiyle bilinen Crataegus L. cinsi Rosaceae familyasının bir üyesidir. Yaprak döken dikenli ağaç ve çalılardan oluşmaktadır. Yaprakları basit veya loblu, çiçekleri korimbuslarda; meyveleri bakka veya drupa olup sarı, kırmızı, mor veya siyah renktedir [1]. Anavatanı Asya ve Akdeniz ülkeleri olan Crataegus türleri çoğunlukla Kuzey yarıkürenin ılıman bölgelerinde yayılış gösterir.

Dünya genelinde 100'den fazla türü bulunan Crataegus cinsinin ülkemizde 6'sı melez olmak üzere 24 türü bulunmakta, bu türler; 10 tanesi endemik olmak üzere 28 taksonla temsil edilmektedir[2 ve 3]. Eşeyli üremesinde melezlik ve polimorfizm yaygın olarak görüldüğü için sinonim durumunda ve tür sayısında sürekli değişiklikler söz konusudur [4].Cinse ait taksonlar meyve ağacı ve peyzaj amaçlı kullanıma ek olarak tıbbi amaçla da değerlendirilmekte; kalp krizi, damar tıkanıklığı, yüksek kolesterol ve yüksek tansiyonu önleyici, idrar zorluğu, ishal, hafıza kaybı, dikkat eksikliği, göz kanlanması ve kötü nefes kokusunu tedavi edici olarak kullanılmaktadır [5-7]. Yunanistan ve Çin'de türlere ait yaprak ve meyveler taze yada pişirilerek tüketilmekte, komposto, marmelat, sütlü tatlılar, şekerleme ve şeker çubukları yapımında ve sirke, meyve suyu ve diğer alkolsüz içeceklerin üretiminde kullanılmaktadır [8 ve 9]. Ülkemizde de yaygın olmamakla birlikte taze meyve, sirke, marmelat ve yaprak- çiçek çayı olarak piyasada bulunmakta, ayrıca halk arasında çay olarak tüketiminin yapıldı̆̆ bilinmektedir [10 ve 11$]$.

Dünya'da ve Türkiye'de doğal ürünlere yönelimin artmasıyla Crataegus cinsine ait türler de önem kazanmıştır. Meyve, yaprak ve çiçeklerinin insan sağlığı üzerine yaptığı etkileri araştıran çalışmaların sayısı her geçen gün artmaktadır. Yapılan çalışmalar Crataegus türlerinin C vitamini ve mineral maddeler yanında fenolik ve flavonoid bileşikler içerdiğini ve bu bileşiklerin kalp- damar sistemi üzerinde pozitif etkiler göstererek antioksidant, antimikrobiyal, nosiseptif, antiinflamatuar, antihipertensif, kardiovasküler etki gibi farmakolojik özelliklere sahip olduğunu göstermiştir [12-20].

Ülkemizde Crataegus taksonları halk arasında 'alıç, akdiken, beyaz diken, edran, kızlar yemişi, yemişen, haziran' gibi farklı isimlerle bilinmektedir. Bir eserde ise her türe ayrı isim verilmiş ve 'Alıç' ismi sadece Crataegus orientalis için kullanılmıştır [2]. Aynı taksonlar üzerine farklı bölgelerde yapılan pomolojik ve kimyasal araştırmaların farklı sonuçlar vermesi bölgesel araştırmalar yapılması gerektiğini göstermiştir [21-23]. Batı Akdeniz Bölgesi'nde Crataegus cinsine yönelik genel bir araştırmanın bulunmadığı görülmüştür.

$\mathrm{Bu}$ çalışma meyvecilik, peyzaj ve alternatif tıp alanlarında ekonomik değer potansiyeli yüksek olan Crataegus cinsinin Batı Akdeniz Bölgesi’ndeki durumunu ve bazı genel özelliklerini belirlemek amacıyla yapılmıştır. Elde edilen veriler bölgede cins bazında yapılacak çalışmalar için de temel oluşturacaktır. 


\section{Materyal ve Metot}

Çalışmanın materyalini Batı Akdeniz Bölgesi (Antalya, Isparta, Burdur) doğal florasında bulunan Crataegus cinsine ait taksonlar oluşturmuştur. Arazi ve laboratuvar çalışmaları 2012-2015 yılları arasında yürütülmüştür. Literatür bilgileri ve yöre halkının yönlendirmeleri doğrultusunda arazi çalışmaları yapılmış, ön teşhislerle belirlenen farklı takson örneklerinden herbaryumlar hazırlanmış, değişik fenolojik dönemlerde çekilen fotoğraflar da kullanılarak ilgili kaynaklar 1şı̆̆ında taksonlar teşhis edilmiştir[2 ve 24]. Her taksonu ve yaygın lokasyonu temsil edecek şekilde meyve morfolojisi/ verimi (homojen görünümde, hastalıksız, örnekleme için yeterli miktarı sağlayan) ve lokasyon mevkii (ulaşılabilirlik, çiçek ve meyvelerin korunurluğu) dikkate alınarak örnek seçimi yapılmıştır. Bitki teşhisi Prof. Dr. A. Ali Dönmez tarafından yapılmış, herbaryum ve kurutulmuş/ dondurulmuş meyve örnekleri Batı Akdeniz Tarımsal Araştırma Enstitüsü Müdürlüğü (BATEM) Gıda Teknolojisi ve Tıbbi Bitkiler Bölümü herbaryumunda muhafaza edilmiştir. Ölçüm ve analizler bölgede doğal yayılış gösteren 5 Crataegus türüne ait 7 taksonu temsil eden 12 ağaçta yapılmıştır. Taksonlar ve lokasyonlara ait genel bilgiler Tablo 1'de sunulmuştur.

Tablo 1. Batı Akdeniz Bölgesi Crataegus taksonları ve lokasyonlarına ait bilgiler

\begin{tabular}{|c|c|c|c|c|}
\hline Taksonlar & $\begin{array}{l}\text { Meyve } \\
\text { rengi }\end{array}$ & Lokasyon adı & $\begin{array}{l}\text { Lokasyon } \\
\text { özelliği }\end{array}$ & Rakım (m) \\
\hline \multirow[t]{3}{*}{ C. orientalis var orientalis Pall. ex M.Bieb.- Alıç } & Kırmızı & Burdur- Halıcılar & Yayla, dağlık & 1399 \\
\hline & Sar1 & Burdur-Günalan & Yol kenarı, tarla & 1219 \\
\hline & Sar1 & Isparta Davraz Dağı-Çobanisa & Mera, otlaklık & 1316 \\
\hline \multirow[t]{4}{*}{ C. monogyna subs. monogyna Jacq.-Yemişen } & Kırmızı & $\begin{array}{c}\text { Isparta- Davraz Dağ1- } \\
\text { Çobanisa }\end{array}$ & Yol Kenarı, Tepelik & 1288 \\
\hline & Kırmızı & Burdur Beşkonak Köyü & Yol Kenarı, Bağ & 775 \\
\hline & Kırmızı & Antalya-Elmalı-Çukurelma & Yol Kenarı, Bağ & 1162 \\
\hline & Kırmızı & Antalya-Aksu & $\begin{array}{c}\text { BATEM Koleksiyon } \\
\text { Bahçesi }\end{array}$ & 15 \\
\hline C. monogyna subs. lasiocarpa(Lange) K.I.Chr.- Yemișen & Kirmız1 & Antalya-Aksu-Kumköy & Çam ormanı içi & 10 \\
\hline C.azarolus var. minuta*( $\left.{ }^{\text {Endemik}}\right)-$ Müzmüldek & Sar1 & Antalya-Elmalı Çukurelma & Yol Kenarı, Bağ & 1148 \\
\hline C. azarolus var. azarolus L.Müzmüldek & Sar1 & Isparta Davraz Dağı-Çobanisa & Tepelik, otlaklık & 1300 \\
\hline C. $x$ sinaica Boiss.- Çöl Alıcı & Bordo & Isparta- Eğirdir İlçe Girişi & Yol Kenarı, Tepelik & 1051 \\
\hline C. rhipidophylla var. rhipidophylla Gand.- Kızılcırık & Kırmız1 & Isparta Davraz Dağı-Çobanisa & Taşlık, Meşelik & 1300 \\
\hline
\end{tabular}

\subsection{Morfolojik özellikler}

Taksonlara ait ağaçların her bakısından olacak şekilde alınan; meyve, yaprak, çiçek ve tohum örneklerinde ölçüm ve sayımlar yapılmıştır. Meyvede; en, boy, çap (mm) uzunlukları, renk ölçümü, meyve ağırlı̆̆ı (g), meyvedeki tohum sayısı (adet) ve tohum ağırlığı (g), yapraklarda; en, boy (mm) ve renk ölçümü, çiçeklerde; kümedeki çiçek adeti ve çiçek çap1 (mm) değerleri belirlenmiştir [25]. Bazı taksonlarda çiçek döneminde yapraklar çok küçük olduğundan, tüm ölçümler meyve döneminde örneklenen yapraklarda yapılmıştır. Renk ölçümlerinde Konica Minolta renk ölçüm cihazı, uzunluk ve ağırlık ölçümlerde dijital kumpas (Digitalmeter) ve hassas terazi (Precisa XB 220A) kullanılmıştır. 


\subsection{Biyokimyasal özellikler}

\subsubsection{Meyvede Toplam Nem}

Meyve örnekleri petri kabı içinde doğranarak paçal yapılmış ve örneklerden kurutulduktan sonra darası alınmış petri kabına $0.1 \mathrm{mg}$ hassasiyetle yaklaşık $5 \pm 0.001 \mathrm{~g}$ tartılarak etüvde (MMM Venticell) $72{ }^{\circ} \mathrm{C}$ de sabit ağırlığa gelene kadar (48 saat) kurutulmuş ve nem kaybı hesaplanmıştır [25].

\subsubsection{Meyvede Toplam Kül}

Meyve örnekleri petri kabı içinde doğranarak paçal yapılmış ve örneklerden kurutulduktan sonra darası alınmış yakma kabına $0.1 \mathrm{mg}$ hassasiyetle yaklaşık $2 \mathrm{~g}$ tartılmıştır. Yakma kapları kül firınında (Protherm) $500 \pm 25^{\circ} \mathrm{C}$ 'de tamamen yakılıp (24 saat) tartılarak kül miktarı saptanmıştır [25].

\subsubsection{Meyvede pH ve Titrasyon Asitliği Analizi}

Paçal yapılan meyve örneklerinden 3'er gram tartılmış $27 \mathrm{ml}$ distile su ile parçalayıcıda homojenize edilmiş vorteks işlemi ardından pH metre (Metter Toledo) kullanılarak pH ölçümü ve 0,1 N NaOH ile titrasyon işlemi gerçekleştirilmiş, seyreltme faktörü dikkate alınarak sitrik asit cinsinden hesaplama yapılmıştır [26].

\subsection{Meyvede Suda Çözünen Kuru Madde Miktarının Belirlenmesi}

Örneklerdeki suda çözünen kuru madde miktarı refraktometre (Krüss) ile ölçülerek belirlenmiştir. Meyve örnekleri petri kabı içinde paçal yapıldıktan sonra 3'er gram tartılmış $27 \mathrm{ml}$ distile su ile parçalayıcıda homojenize edilmiş vorteks işlemi ardından refraktometre (Krüss) kuyucuğuna örnek aktarılarak brix değeri okunmuş ve seyreltme faktörü dikkate alınarak hesaplama yapılmıştır [26].

\subsection{Verilerin Dĕgerlendirilmesi}

Morfolojik ölçümler 3 tekerrürlü ve her tekerrürde 10 örnek olacak şekilde yapılmış, renk ölçümleri ve analizler ise iki tekerrürlü olarak yürütülmüştür. Elde edilen sonuçlar istatistiki farklılıkların belirlenmesi amacıyla Genel Linear Model Esası ile \%5 ve \%1 önemlilik seviyelerine göre varyans analizi ve Duncan Çoklu Karşılaştırma Testine tabi tutulmuştur [27].

\section{Bulgular}

Araştırma sonucunda belirlenen taksonlar ve örnekleme yapılan lokasyonlara ait bilgiler Tablo 1'de, lokasyonların harita üzerinde gösterimi ise Şekil 1'de sunulmuştur. Bölgede Crataegus cinsinin deniz seviyesinden (Antalya Aksu10m, C. monogyna), 1400 m’ye (Burdur Halıcılar Köyü- C. orientalis kırmızı meyveli örneği) kadar yayılış gösterdiği ve 1000 m yükselti altında sadece $C$. monogyna türünün bulunduğu görülmüştür. Bulgular bölge florasına ait literatür bilgilerinden bazı değişiklikler göstermiştir. Bölge flora kayıtlarında geçmeyen, Akdeniz Bölgesi’nin Adana Bölümü ile sınırlı kalan [2], C. rhipidophylla subsp. rhipidophylla taksonunun tek bir ağaççık olarak bölgede bulunduğu görülmüş ve çalışmaya dâhil edilmiştir (çiçek ve yaprak örneği alınmış, meyve örneği temin edilememiştir). Bölge için Türkiye flora kaynaklarında geçmeyen, İran florası [28] kapsamında varlığı belirtilen Crataegus pentagyna Waldst.\& Kit. et Willd. türü bu bilgiye istinaden çalışma kapsamına alınmış, ancak Avrupa Sibirya elementi olan türe belirtilen bölgede yapılan arazi taramalarında rastlanılmamıştır. Ayrıca Akdeniz Bölgesi endemiği olarak geçmekte iken, C. azarolus var. azarolus taksonu altında sinonim yapılan C. azarolus var. minuta taksonu ayrı bir takson şeklinde tanımlanmıştır. 


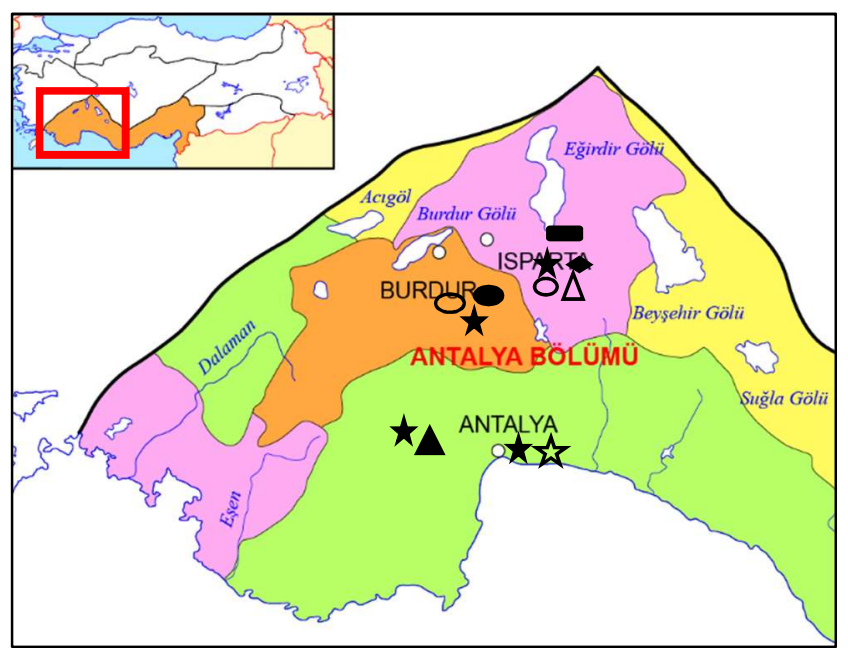

C. orientalis(Sarı meyveli)

C. orientalis(Kırmızı meyveli)

AC. azarolus var. minuta

$\triangle$ C. azarolus var. azarolus

C. $\mathrm{x}$ sinaica

†C. monogyna subs. monogyna

起C. monogyna subs. lasiocarpa

C.rhipidophylla

Şekil 1. Çalışma kapsamında örnekleme yapılan lokasyonlar

Araştırmada Crataegus taksonlarının meyve ve tohum örneklerinde bazı morfolojik ve biyokimyasal özelliklere ait verilerle yapılan analiz sonucunda özellikler arasında istatistiki olarak \%1 düzeyinde önemli farklılık olduğu bulunmuştur (Tablo 2). Meyve ölçümleri boy, en, ağırlık ve tohum sayısı bakımından en yüksek değerlerin tohum (çekirdek-piren) sayısı fazla olan $C$. orientalis ve $C$. azarolus taksonlarına ait olduğunu; tohum ağırlığının ise tek çekirdekli $C$. monogyna ve $C$. $x$ sinaica örneklerinde olduğunu göstermiştir. Meyvelerde boy 7.41- 10.64 mm, en 7- 9.69 mm, ağırlık 0.42- 0.72 g, tohum ağırlığ $0.08-0.16 \mathrm{~g}$ arasında değişmiştir.

Tablo 2.Crataegus taksonları meyve ve tohum örneklerinde bazı morfolojik ve biyokimyasal özellikler

\begin{tabular}{|c|c|c|c|c|c|c|c|c|c|c|}
\hline Örnekler & $\begin{array}{l}\text { Boy } \\
(\mathrm{mm})\end{array}$ & $\begin{array}{c}\text { En } \\
(\mathrm{mm})\end{array}$ & Ağırlık (g) & $\begin{array}{c}\text { Tohum } \\
\text { sayısı (adet) }\end{array}$ & $\begin{array}{c}\text { Tohum } \\
\text { Ağırlığ̀ (g) }\end{array}$ & $\begin{array}{l}\text { Kül } \\
(\%)\end{array}$ & Nem (\%) & $\begin{array}{c}\text { SÇKM } \\
(\%)\end{array}$ & $\mathrm{pH}$ & $\begin{array}{c}\text { Asitlik } \\
(\%)\end{array}$ \\
\hline SorB*** & $14.67 \mathrm{a}^{*}$ & $17.45 \mathrm{a}$ & $3.13 \mathrm{a}$ & $3.75 \mathrm{ab}$ & $0.1193 \mathrm{ac}$ & $0.42 \mathrm{~d}$ & $78.55 \mathrm{a}$ & $13.50 \mathrm{~d}$ & $3.37 \mathrm{f}$ & $1.16 \mathrm{~d}$ \\
\hline SorD & $14.01 \mathrm{ab}$ & $17.45 \mathrm{a}$ & $2.93 \mathrm{a}$ & $3.46 \mathrm{~b}$ & $0.1232 \mathrm{ac}$ & $0.36 \mathrm{~d}$ & $78.05 \mathrm{a}$ & $17.50 \mathrm{bc}$ & $3.20 \mathrm{~g}$ & $1.88 \mathrm{a}$ \\
\hline Kor & $13.47 \mathrm{bc}$ & $16.25 \mathrm{~b}$ & $2.30 \mathrm{~b}$ & $3.79 \mathrm{a}$ & $0.0829 \mathrm{c}$ & $0.59 \mathrm{~d}$ & $77.45 \mathrm{ab}$ & $16.00 \mathrm{c}$ & $3.39 \mathrm{f}$ & $0.86 \mathrm{~g}$ \\
\hline Min & $12.95 \mathrm{c}$ & $14.91 \mathrm{c}$ & $1.74 \mathrm{c}$ & $2.58 \mathrm{c}$ & $0.1229 \mathrm{ac}$ & $1.00 \mathrm{c}$ & $64.82 \mathrm{f}$ & $12.50 \mathrm{~d}$ & $3.40 \mathrm{f}$ & $1.29 \mathrm{~b}$ \\
\hline Azar & $11.86 \mathrm{~d}$ & $12.90 \mathrm{~d}$ & $1.52 \mathrm{c}$ & $2.83 \mathrm{c}$ & $0.1213 \mathrm{ac}$ & $1.25 \mathrm{bc}$ & $61.35 \mathrm{~g}$ & $13.50 \mathrm{~d}$ & $3.55 \mathrm{e}$ & $1.89 \mathrm{a}$ \\
\hline Sin & $8.23 \mathrm{fg}$ & $8.50 \mathrm{f}$ & $0.59 \mathrm{~d}$ & $1.00 \mathrm{~d}$ & $0.1309 a b$ & $1.66 \mathrm{ab}$ & $69.16 \mathrm{~d}$ & $19.50 \mathrm{a}$ & $3.84 \mathrm{~b}$ & $1.12 \mathrm{e}$ \\
\hline MonoD & $7.41 \mathrm{~g}$ & $7.31 \mathrm{gh}$ & $0.50 \mathrm{~d}$ & $1.00 \mathrm{~d}$ & $0.1303 \mathrm{ac}$ & $1.68 \mathrm{ab}$ & $69.70 \mathrm{~d}$ & $16.00 \mathrm{c}$ & $4.05 \mathrm{a}$ & $0.88 \mathrm{~g}$ \\
\hline MonoB & $7.84 \mathrm{fg}$ & $7.03 \mathrm{~h}$ & $0.42 \mathrm{~d}$ & $1.00 \mathrm{~d}$ & $0.0879 \mathrm{bc}$ & $1.00 \mathrm{c}$ & $70.23 \mathrm{~d}$ & $16.50 \mathrm{c}$ & $3.74 \mathrm{c}$ & $1.20 \mathrm{c}$ \\
\hline MonoE & $10.64 \mathrm{e}$ & $8.12 \mathrm{gf}$ & $0.43 \mathrm{~d}$ & $1.00 \mathrm{~d}$ & $0.1155 b c$ & $1.78 \mathrm{a}$ & $66.63 \mathrm{e}$ & $18.50 \mathrm{ab}$ & $3.77 \mathrm{bc}$ & $1.05 \mathrm{f}$ \\
\hline MonoBah & $8.48 \mathrm{f}$ & $9.69 \mathrm{e}$ & $0.72 \mathrm{~d}$ & $1.08 \mathrm{~d}$ & $0.1657 \mathrm{a}$ & $1.61 \mathrm{ab}$ & $75.57 \mathrm{c}$ & $10.50 \mathrm{e}$ & $3.83 \mathrm{bc}$ & $0.78 \mathrm{~h}$ \\
\hline Lasio & $8.16 \mathrm{fg}$ & $8.83 \mathrm{ef}$ & $0.44 \mathrm{~d}$ & $1.00 \mathrm{~d}$ & $0.1123 b c$ & $2.04 \mathrm{a}$ & $76.76 \mathrm{~b}$ & $8.75 \mathrm{e}$ & $3.65 \mathrm{~d}$ & $1.15 \mathrm{ed}$ \\
\hline Rhipi & \multicolumn{10}{|c|}{ Meyve örneği temin edilememiştir } \\
\hline $\mathrm{CV}$ & 10.32 & 9.98 & 31.05 & 21.12 & 53.13 & 11.48 & 0.5 & 4.01 & 0.75 & 0.66 \\
\hline LSD & 0.82 & 0.87 & 0.31 & 0.32 & 0.05 & 0.45 & 1.15 & 1.88 & 0.09 & 0.03 \\
\hline Önemlilik & ** & $* *$ & $* *$ & ** & ** & ** & $* *$ & $* *$ & ** & $* *$ \\
\hline
\end{tabular}

*Her sütunda aynı harfle gösterilen ortalamalar arasında 0.05 düzeyinde istatistiki olarak fark yoktur.** (\%1) düzeyinde önemli.***(SorB: Sarı meyveli $C$. orientalis Burdur, SorD: Sarı meyveli $C$. orientalis Davraz, Kor: Kırmızı meyveli C. orientalis, Min: $C$. azarolus var. minuta, Azar: $C$. azarolus var. azarolus, Sin: C. x sinaica, MonoD: C. monogyna subs. monogyna Davraz, MonoB: C. monogyna subs. monogyna Burdur, MonoE: C. monogyna subs. monogyna Elmalı, MonoBah: C. monogyna subs. monogyna Bahçe, Lasio: C. monogyna subs. lasiocarpa, Rhipi: C.rhipidophylla).

Meyve örnekleri içinde kül oranı en yüksek C. monogyna var. lasiocarpa ve C. monogyna (Elmalı örneği), en düşük ise $C$. orientalis örnekleri olmuştur. Nem oranı en yüksek C. orientalis meyvelerinde, en düşük ise $C$. azarolus örneklerinde görülmüştür. Suda çözünen kuru madde miktarı taksonlar ve örnekler bazında farklılık göstermiş, en yüksek değerleri C. x sinaica, C. monogyna (Elmalı örneği) ve C. orientalis sarı meyveli Davraz örnekleri vermiştir. pH 
Nevşehir Bilim ve Teknoloji Dergisi (2020), 9(1) 63-72

ölçümlerinde en yüksek değerleri C. monogyna ve C. $x$ sinaica örnekleri vermiş, asitliğin en yüksek olduğu taksonlar ise C. orientalis sarı meyveli Davraz örneği ve C. azarolus taksonları olmuştur.

Meyve örneklerinde renk ölçüm sonuçları tüm parametreler için farklılıkların \%1 düzeyinde önemli olduğunu göstermiştir. Renk ölçümlerinde sonuçlar hue $\left(\mathrm{H}^{\circ}\right)$ renk göstergesine göre değerlendirilmiş [29], örnekler içinde en kırmızı rengi $\left(\mathrm{H}^{\circ}=15.21\right)$ C. $x$ sinaica, en sarı rengi $\left(\mathrm{H}^{\circ}=61.52\right)$ C. orientalis sarı meyveli Davraz, en yeşilimsi rengi $\left(\mathrm{H}^{\circ}=90.04\right)$ C. azarolus var. minuta taksonları vermiştir. Renk yoğunluğunun en fazla olduğu taksonlar $C$. orientalis ve C. azarolus taksonları olmuştur. Meyve renk ölçüm sonuçları Tablo 3'de verilmiştir.

Tablo 3.Crataegus taksonları meyve örneklerinde renk ölçüm sonuçları

\begin{tabular}{|c|c|c|c|c|c|}
\hline Örnekler & $\mathrm{L}_{\mathrm{X}}$ & $a_{x}$ & $\mathrm{~b}_{\mathrm{X}}$ & $\mathrm{c}_{\mathrm{X}}$ & $\mathrm{H}^{\circ}$ \\
\hline SorB*** & $71.79 b^{*}$ & $14.08 \mathrm{e}$ & $65.73 \mathrm{a}$ & $67.23 \mathrm{a}$ & $77.91 \mathrm{~b}$ \\
\hline SorD & $64.80 \mathrm{c}$ & $24.04 \mathrm{~d}$ & $44.81 \mathrm{c}$ & 50.99 bd & $61.52 \mathrm{c}$ \\
\hline Kor & $44.08 \mathrm{~d}$ & $49.35 \mathrm{a}$ & $32.88 \mathrm{~d}$ & $59.31 \mathrm{ab}$ & $33.65 \mathrm{~d}$ \\
\hline Min & $81.53 \mathrm{a}$ & $0.46 \mathrm{f}$ & $52.53 \mathrm{~b}$ & $52.53 \mathrm{bd}$ & $90.04 \mathrm{a}$ \\
\hline Azar & $72.03 \mathrm{~b}$ & $3.18 \mathrm{f}$ & $54.76 \mathrm{~b}$ & $54.85 \mathrm{bc}$ & $86.68 \mathrm{a}$ \\
\hline Sin & $28.92 \mathrm{~g}$ & $34.00 \mathrm{c}$ & $9.36 \mathrm{~g}$ & $35.28 \mathrm{e}$ & $15.21 \mathrm{~h}$ \\
\hline MonoD & $29.70 \mathrm{~g}$ & $35.64 \mathrm{bc}$ & $11.87 \mathrm{fg}$ & 37.57 ef & $18.91 \mathrm{gh}$ \\
\hline MonoB & $32.68 \mathrm{f}$ & $40.48 \mathrm{bc}$ & $17.56 \mathrm{ef}$ & $44.14 \mathrm{ed}$ & $23.40 \mathrm{fg}$ \\
\hline MonoE & $37.06 \mathrm{e}$ & $42.41 \mathrm{ab}$ & $21.60 \mathrm{e}$ & $39.65 \mathrm{ef}$ & $27.56 \mathrm{ef}$ \\
\hline MonoBah & $45.00 \mathrm{~d}$ & $41.34 \mathrm{ab}$ & $27.98 \mathrm{~d}$ & $49.92 \mathrm{~cd}$ & $34.07 \mathrm{~d}$ \\
\hline Lasio & $36.19 \mathrm{e}$ & $36.02 \mathrm{bc}$ & $21.31 \mathrm{ef}$ & $49.35 \mathrm{~cd}$ & $29.97 \mathrm{de}$ \\
\hline Rhipi & \multicolumn{5}{|c|}{ Meyve örneği temin edilememiştir } \\
\hline $\mathrm{CV}$ & 1.83 & 8.70 & 5.87 & 5.58 & 3.19 \\
\hline LSD & 2.87 & 8.05 & 6.09 & 8.69 & 4.58 \\
\hline Önemlilik & $* *$ & $* *$ & $* *$ & $* *$ & $* *$ \\
\hline
\end{tabular}

Çiçeklerde kümede çiçek adedi ve çiçek çapı değerleri sırasıyla 3.88-13.20 adet arası ve 10.20-20.20mm arasında değişiklik göstermiş, farkl11ıkların \%1 düzeyinde önemli olduğu görülmüştür(Tablo 4).Kümede çiçek adedi en fazla $C$. monogyna Burdur ve Elmalı örneklerinde sayılırken, en az ağaççık şeklinde olan, C. rhipidopylla ve C. monogyna Davraz örneklerinde sayılmıştır. Çiçek çapı en yüksek, iri meyveli tür olan C. orientalis örnekleri olmuş, onları C. rhipidopylla, C. x sinaica ve C. monogyna var. monogyna örnekleri izlemiştir. C. azarolus taksonlarında ise meyveler, C. monogyna meyvelerinden daha iri olmalarına rağmen çiçek çapları daha küçük olmuştur.

Yaprak örneklerinde en uzun boy ölçümü $C$. orientalis sarı meyveli Burdur örneğinde, en geniş en ölçümü $C$. rhipidopylla örneğinde belirlenmiştir. C. azarolus var. azarolus ve C. monogyna Davraz örnekleri ağaççk şeklinde olduğundan yaprak büyüklükleri diğer örneklere kıyasla küçük bulunmuş, ancak yine ağaççık şeklinde olan $C$. rhipidopylla yaprakları ise $C$. orientalis türü yaprakları gibi büyük boyutlarda olmuştur. Yapraklara ilişkin ölçüm sonuçları boy ve en ölçümleri \%1 düzeyinde önemli farklıllkta bulunmuş ve sonuçlar Tablo 4'de verilmiştir.

Yaprak örneklerinde renk ölçüm sonuçlarında yeşil rengi temsil eden "a" ifadesinin eksi değerleri görülmüş, en düşük değerler C. monogyna Burdur, Elmalı ve bahçe örneklerinde ölçülürken, en yüksek değerler $C$. rhipidopylla ve $C$. orientalis taksonlarında ölçülmüştür. Sonuçlar hue renk göstergesine göre değerlendirildiğinde en yeşil renk C. monogyna ve $C$. $x$ sinaica taksonlarında olurken, sarıya en yakın renk C. orientalis Davraz örneğinde olmuştur. 
Nevşehir Bilim ve Teknoloji Dergisi (2020), 9(1) 63-72

\begin{tabular}{|c|c|c|c|c|c|c|c|c|c|}
\hline \multirow[t]{2}{*}{ Örnekler } & \multicolumn{2}{|c|}{ Çiçek örneklerinde } & \multicolumn{2}{|c|}{ Yaprak örneklerinde } & \multirow[b]{2}{*}{$\mathrm{L}_{\mathrm{X}}$} & \multirow[b]{2}{*}{$a_{x}$} & \multirow[b]{2}{*}{$b_{X}$} & \multirow[b]{2}{*}{$\mathrm{c}_{\mathrm{X}}$} & \multirow[b]{2}{*}{$\mathrm{H}^{\circ}$} \\
\hline & Kümede adet & Çap (mm) & Boy $(\mathrm{mm})$ & $\operatorname{En}(\mathrm{mm})$ & & & & & \\
\hline SorB $* * *$ & $8.75 \mathrm{bc}^{*}$ & $19.62 \mathrm{a}$ & $40.00 \mathrm{a}$ & $37.40 \mathrm{ab}$ & $36.21 \mathrm{c}$ & $-7.36 \mathrm{ab}$ & $17.38 \mathrm{ce}$ & $18.87 \mathrm{dc}$ & $113.04 \mathrm{bc}$ \\
\hline SorD & $9.40 \mathrm{~b}$ & $18.33 \mathrm{a}$ & $36.30 \mathrm{~b}$ & $31.10 \mathrm{c}$ & $51.14 \mathrm{a}$ & $-5.20 \mathrm{a}$ & $17.59 \mathrm{ce}$ & $17.97 \mathrm{dc}$ & $98.82 \mathrm{~d}$ \\
\hline Kor & $8.70 \mathrm{bc}$ & $20.20 \mathrm{a}$ & $34.80 \mathrm{~b}$ & $30.00 \mathrm{c}$ & $38.67 \mathrm{bc}$ & $-4.35 \mathrm{a}$ & $13.64 \mathrm{e}$ & $14.38 \mathrm{~d}$ & $107.61 \mathrm{bc}$ \\
\hline Min & $10.70 \mathrm{ab}$ & $10.20 \mathrm{~g}$ & $18.20 \mathrm{e}$ & $19.00 \mathrm{~d}$ & $41.58 \mathrm{bc}$ & $-10.69 \mathrm{~cd}$ & $19.03 \mathrm{ce}$ & $20.61 \mathrm{bc}$ & $107.03 \mathrm{bc}$ \\
\hline Azar & $9.70 \mathrm{~b}$ & $11.85 \mathrm{f}$ & $15.80 \mathrm{e}$ & $17.70 \mathrm{~d}$ & $50.81 \mathrm{a}$ & $-10.31 b d$ & $23.73 \mathrm{bc}$ & $25.88 \mathrm{ba}$ & $113.64 \mathrm{bc}$ \\
\hline Sin & $10.00 \mathrm{~b}$ & $15.25 \mathrm{~b}$ & $34.30 \mathrm{~b}$ & $32.70 \mathrm{c}$ & $34.59 \mathrm{c}$ & $-9.03 b c$ & $18.01 \mathrm{ce}$ & $20.15 b c$ & $116.60 \mathrm{ab}$ \\
\hline MonoD & $6.40 \mathrm{~cd}$ & $14.65 \mathrm{bc}$ & $19.00 \mathrm{e}$ & $18.50 \mathrm{~d}$ & $45.46 \mathrm{ab}$ & $-9.97 \mathrm{bd}$ & $26.52 \mathrm{a}$ & $28.36 \mathrm{a}$ & $110.85 \mathrm{bc}$ \\
\hline MonoB & $13.20 \mathrm{a}$ & $13.55 \mathrm{~cd}$ & $30.30 \mathrm{c}$ & $30.10 \mathrm{c}$ & $39.67 \mathrm{bc}$ & $-13.07 \mathrm{~d}$ & $23.35 \mathrm{bc}$ & $26.76 \mathrm{ba}$ & $119.23 \mathrm{ab}$ \\
\hline MonoE & $11.20 \mathrm{ab}$ & $12.90 \mathrm{df}$ & $35.30 \mathrm{~b}$ & $39.40 \mathrm{a}$ & $45.21 \mathrm{ab}$ & $-12.37 \mathrm{~d}$ & $25.39 \mathrm{ab}$ & $28.26 \mathrm{a}$ & $115.91 \mathrm{ab}$ \\
\hline MonoBah & $8.70 \mathrm{bc}$ & $14.20 \mathrm{~cd}$ & $30.00 \mathrm{c}$ & $29.20 \mathrm{c}$ & $38.25 \mathrm{bc}$ & $-11.19 \mathrm{~cd}$ & $16.48 \mathrm{de}$ & $19.94 \mathrm{bc}$ & $124.41 \mathrm{a}$ \\
\hline Lasio & $9.40 \mathrm{~b}$ & $12.30 \mathrm{ef}$ & $30.10 \mathrm{c}$ & $29.40 \mathrm{c}$ & $41.58 \mathrm{bc}$ & $-10.04 b d$ & 20.18 ce & $22.52 \mathrm{bc}$ & $116.31 \mathrm{ab}$ \\
\hline Rhipi & $3.88 \mathrm{~d}$ & $15.50 \mathrm{~b}$ & $36.90 \mathrm{ab}$ & $42.20 \mathrm{a}$ & $36.17 \mathrm{c}$ & $-4.35 \mathrm{a}$ & $19.58 \mathrm{ce}$ & $20.01 \mathrm{bc}$ & $102.41 \mathrm{~cd}$ \\
\hline $\mathrm{CV}$ & 23.71 & 8.83 & 10.02 & 14.9 & 6.81 & -11.42 & 11.34 & 10.23 & 3.88 \\
\hline LSD & 2.56 & 1.51 & 3.69 & 5.41 & 8.81 & 3.19 & 7.07 & 6.98 & 13.03 \\
\hline Önemlilik & $* *$ & $* *$ & $* *$ & $* *$ & $* *$ & $* *$ & $* *$ & $* *$ & $* *$ \\
\hline
\end{tabular}

*Her bir sütunda aynı harfle gösterilen ortalamalar arasında 0.05 düzeyinde istatistiki olarak fark yoktur. ** (\%1) düzeyinde önemli.***(SorB: Sarı meyveli $C$. orientalis Burdur, SorD: Sarı meyveli $C$. orientalis Davraz, Kor: Kırmızı meyveli C. orientalis, Min: $C$. azarolus var. minuta, Azar: $C$. azarolus var. azarolus, Sin: C. x sinaica, MonoD: C. monogyna subs. monogyna Davraz, MonoB: C. monogyna subs. monogyna Burdur, MonoE: . monogyna subs. monogyna Elmalı, MonoBah: C. monogyna subs. monogyna Bahçe, Lasio: C. monogyna subs. lasiocarpa, Rhipi: C.rhipidophylla).

\section{Tartışma ve Sonuç}

Çalışmada bölgedeki Crataegus taksonlarının genel dağılımları ve bazı morfolojik ve biyokimyasal özellikleri belirlenmiş̧ir. Doğada bolluk açısından en yaygın taksonlar C. monogyna var. monogyna ve C. orientalis var. orientalis (sarı meyveli) olurken, gençleşme bakımından C. azarolus ön plana çıkmış ve türe ait çok sayıda fidan tespit edilmiştir. Meyve morfolojik ölçümlerinde $C$. orientalis ve $C$. azarolus taksonları iri meyveleri ile meyve olarak değerlendirilebilecek taksonlar olurken, C. monogyna, C. azarolus var minuta ve C. orientalis çiçek yapısı, çiçek kümesi ve meyve tutumu bakımlarından oldukça dekoratif bulunmuş ve peyzaj düzenlemeleri kapsamında daha yaygın kullanılması gerektiği düşünülmüştür.

Önemli bir kalite ölçütü olarak değerlendirilen meyve özellikleri bakımından meyve iriliği dikkat çekici bir parametre olarak ele alınmaktadır. Türkoğlu ve ark. [30]yaptıkları çalışmada; Van'ın Gevaş ve Edremit ilçelerinde yetişen Crataegus taksonlarında (C. orientalis, C. curvisephala, C. pentagyna; C. monogyna subsp. azarella ve C. monogyna var. monogyna) pomolojik analizlerinde, meyve boyu, eni ve ağırlığı bakımından $C$. orientalis en yüksek değerleri sırasıyla $14.68 \mathrm{~mm}, 17.81 \mathrm{~mm}, 2.34 \mathrm{~g}$ olarak verirken, en düşük değerleri C. monogyna var. monogyna sirasıyla $11.05 \mathrm{~mm}, 10.35$ $\mathrm{mm}, 0.71 \mathrm{~g}$ olarak vermiştir. Ayrıca $C$. orientalis' in en yükssek tohum sayısına (4.47 adet), en düşük tohum ağırlığına ( 0.08 g) sahip olduğu belirtilmiştir. Bu çalışmada da C.orientalis'e ait 3 genotip meyve boyu, eni ve ağırlığı bakımından en yüksek değerleri verirken, ölçümlerin en düşük değerleri C. monogyna' ya ait 5 genotipte ve $C$. x sinaica' da olmuştur. Sonuçlar taksonlar bazında değişen veriler için uyumlu bulunmuştur.

Konya-Derbent'te yetişen alıç (Crataegus sp.) meyvelerinde yapılan ölçümlerde; ortalama tohum ağırlığı $0.87 \mathrm{~g}$, uzunluk 14.39 mm, kütle $3.03 \mathrm{~g}$, kül \%2.28, asitlik \%1.98, pH 3.38 ve suda çözünen ekstrakt \%32.31 bulunmuştur [13]. Morfolojik ölçüm sonuçları bölge C. orientalis genotipleri ile uyumlu gözükürken, tohum ağırlığı ve suda çözünen ekstrakt değerleri bölge Crataegus taksonlarından farklı olmuştur. Çalışmada materyaller tür düzeyinde tanımlanmadığından, taksonlar bazında kıyaslama yapılamamış, asitlik ve $\mathrm{pH}$ değerleri $C$. orientalis ile uyumlu gözükürken, kül değeri bölge taksonlarından yüksek değer vermiştir. 
Nevşehir Bilim ve Teknoloji Dergisi (2020), 9(1) 63-72

Van'ın Gevaş ve Edremit ilçelerinde yapılan diğer bir çalışmada; C. azarolus seleksiyonu yapılmıştır. Meyve ağırlıkları 0.81- 2.14 g, SÇKM oranı \%12.20- 27.20, pH 3.47- 4.45, tohum ağırlıkları 0.17- 0.55 g, meyve eni 10.74$17.06 \mathrm{~mm}$ ve meyve boyu 10.65-15.49 mm arasında bulunmuştur [31]. Aynı tür için bu çalışmada elde edilen verilerin seleksiyon değerlerinin içinde olduğu görülmüştür. Hatay’da yaygın olarak yetiştiriciliği yapılan sarı alıç $(C$. azarolus)genotipinde ise beş yıllık ortalama ölçümlere göre, meyve ağırlı̆̆ $15.03 \mathrm{~g}$, meyve eni $32.03 \mathrm{~mm}$, meyve boyu $26.88 \mathrm{~mm}$, tohum sayısı 2.4 adet, tohum ağırlığı $0.7 \mathrm{~g}$, SÇKM içeriği \%15, pH 3.2 ve asitlik \%1.4 olarak saptanmıştır [32] ve SÇKM, pH ve asitlik değerleri uyumlu olsa da, meyve ve tohum iriliğinin yetiştiriciliği yapılan genotipte oldukça büyük olduğu görülmüştür.

Van'da bulunan Crataegus genotipleri meyvelerinin bazı biyokimyasal parametrelerine bakıldığında $\mathrm{pH}$, asitlik, kuru madde ve SÇKM değerlerinin sırasıyla $C$. orientalis genotipleri için 3.12-3.67, 0.49-0.96,16.7-32.74 ve 11.66-18.50 arasında olduğu görülmüştür. C. monogyna genotipleri için ise aynı değerler sırasıyla; 3.31- 4.09,0.48- 0.99, 21.83- 42.60 ve 13.50- 23.86 arasında olduğu olmuştur[30]. Van Bölgesi'ndeki Crataegus genotiplerinde asitlik daha yüksek olurken, diğer veriler her iki tür için de bölgemizle uyumlu olmuştur. Çorum'da yetişen Crataegus cinsine ait 51 genotip örneğinde yapılan incelemede; meyve ağırlığı 1.54-4.72 g, meyve boyu 5.86-24.23 mm, meyve eni 13.21-21.46 mm, çekirdek sayıs1 3-5 adet ve çekirdek ağırlığı 0.32-0.9 g arasında bulunmuştur [33]. Ölçüm sonuçları genel olarak Çorum'da yayılış gösteren Crataegus genotiplerinin bölge genotiplerinden daha iri olduklarını göstermiştir. Ancak çalışmada tür ve takson bilgisi bulunmadığından tüm verilerin alt ve üst sınırları göz önüne alınarak yorum yapılmış, taksonlar bazında kıyas yapılamamıştır.

Hakkâri- Şemdinli'de Crataegus cinsine ait 39 ağaç üzerinden yapılan bir çalışmada bazı morfolojik ve biyokimyasal özellikler belirlenmiştir. Çalışmada meyve ağırlığı 2.16- $4.89 \mathrm{~g}$, meyve eni15.15-23.20 mm, boyu 14.7219.81 mm, çekirdek sayısı 1.95- 3.47 adet, çekirdek ağırlı̆̆ 0.39- 0.86 g, ve pH \%3.04-4.06, SÇKM \%16.04-25.56, titrasyon asitliği \%0.53-2.76 arasında bulunmuştur [34]. Takson bilgisi verilmeyen çalışmada en yüksek meyve ağırlığının sarı renkli A-4 genotipinde, en düşük meyve ağırlığının ise kırmızı renkli L-9 genotipinde ölçüldüğü belirtilmiştir. Sonuçlar çalışma bölge sonuçları ile kıyaslandığında Hakkâri'de yayılış gösteren Crataegus taksonlarında pH değeri benzer olurken, meyve ve tohumların daha iri, SÇKM ve asitlik değerlerinin ise daha yüksek olduğu görülmüştür.

Meyvelerde yapılan renk ölçüm sonuçlarında $L_{x}$ değeri 36.19- 81.53 arasında, $a_{x}$ değeri 0.46- 49.35 arasında, $b_{x}$ değeri 9.36-65.73 arasında değişmiştir. Crataegus cinsinde türler bazında Minolta cihazı ile yapılan renk ölçümü sonucuna rastlanmamıştır. Ancak Çorum'da yapılan ve cins altı takson bilgisi verilmeyen bir çalışma renk ölçüm sonuçlarının $L_{x}$ değeri için 43.10-72.20 arasında, $a_{x}$ değeri için 0.46-35.22 arasında, $b_{x}$ değer için 22.20-42.03 arasında değiştiğini göstermiştir [33]. Parlaklığı gösteren $L_{x}$ değeri yaklaşık olarak benzerlik göstermiş, kırmızıllğı gösteren $a_{x}$ değeri Çorum genotipleri için 35 üst sınırında belirlenirken, bu bölge için C. monogyna örneklerinde 35-42 arasında, $C$. orientalis kırmızı meyveli örneğinde 49 olarak ölçülmüştür. Batı Akdeniz Bölgesi meyvelerinde kırmızı rengi ifade eden $a_{x}$ değerinin daha yüksek olduğu görülmüştür. Sarıllğ 1 ifade eden $b_{x}$ değeri Çorum genotipleri için 22-42 arasında iken, bu bölge için daha geniş bir aralık vererek; 9 (bordo renkteki C. $x$ sinaica meyvesi) ve 65 (Sarı renkli C. orientalis meyvesi) arasında ölçülmüştür.

Çalışma Batı Akdeniz Bölgesi’nde bulunan Crataegus taksonlarına yönelik genel bir tanımlama niteliğinde olmuştur ve devam edecek araştırmalar için de temel oluşturacağı düşünülmektedir. Bölge florasındaki Crataegus türlerinin tıbbi bitkiler, meyvecilik, peyzaj gibi alanlarda değerlendirilmesi ve yaygın türlerde yapılacak seleksiyon çalışmaları ile belirlenecek ümitvar genotiplerin ekonomiye kazandırılması gerekmektedir. 


\section{Teşekkür}

Bu araştırmayı TAGEM/TBAD/12/A01/P01/007 no'lu proje ile destekleyen Tarımsal Araştırmalar ve Politikalar Genel Müdürlüğü’ne ve taksonların teşhisindeki katkılarından dolayı Prof. Dr. A. Ali Dönmez’e (Hacettepe Üniversitesi) teşekkürlerimizi sunarız.

\section{Kaynaklar}

[1] Seçmen Ö.,“Tohumlu Bitkiler Sistematiği”Ege Üniversitesi Fen Fakültesi Kitaplar Serisi, 396s, İzmir, 1998.

[2] Aslan S., “Crataegus L., Türkiye Bitkileri (Damarlı Bitkiler)” Başeditör: Güner A., Nezahat Gökyiğit Botanik Bahçesi ve Flora Araştırmaları Derneği Yayını, İstanbul, 798-801, 2012.

[3] Sharifnia F., Seyedipour N., Mehregan I., Salimpour F., "Phylogenetic study some of Crataegus L. (Rosaceae, Pyreae) species in Iran”Journal of Biodiversity and Environmental Sciences, 3, 1-11, 2013.

[4] Dönmez A., "The Genus Crataegus L. (Rosaceae) with Special Reference to Hybridisation and Biodiversity in Turkey” Turkish Journal of Botany,28, 29-37, 2004.

[5] Çalışkan O., Gündüz K., Bayazıt S., "Sarı Alıç (Crataegus azarolus L.) Genotipinin Morfolojik, Biyolojik ve Meyve Kalite Özelliklerinin İncelenmesi” Gaziosmanpaşa Üniversitesi Ziraat Fakültesi Dergisi, 35, 69-74, 2018.

[6] Gültekin H. C., "Bozkırın Yalnız Ağaçları Alıçlar” Bilim ve Teknik, 2, 76-78, 2005.

[7] Miandji M. A.,"Tıbbi Bitkiler Atlası”Bilgi Yayınevi, 344s, Ankara, 2010.

[8] Alibertis A.,."Healing-Aromatic and Edible Plants of Crete"Mystis, 351s, Typokreta, 2007.

[9] Dharmananda S.,"Hawthorn (Crataegus) Food and Medicine in China". www.itmonline.org/arts/ crataegus.htm, Erişim tarihi: 15.03.2019.

[10] Altundağ E., Öztürk M., "Ethnomedicinal studies on the plant resources of east Anatolia, Turkey"Procedia Social and Behavioral Sciences, 19, 756-777, 2011.

[11] Polat R., Satıl F., “An ethnobotanical survey of medicinal plants in Edremit Gulf (Balıkesir- Turkey) ”Journal of Ethnopharmacology, 139, 626- 641, 2011.

[12]Zhang Z., Chang Q., Zhu M., Huang Y., Ho W. K. K., Chen Z. Y., "Characterization of antioxidants present in hawthorn fruits" Journal of Nutritional Biochemistry, 12,144-152, 2001.

[13]Özcan M., Hacıseferoğulları H., Marakoğlu T., Arslan D., "Hawthorn (Crataegus spp.) fruit: some physical and chemical properties"Journal of Food Engineering, 69, 409-413, 2005.

[14] Swerdlow J. L. (Ed. G. Kızılkaya). Şifalı Bitkiler- Doğanın Eczanesinden 100 mucize bitki, Doğuş Grubu İletişim Yayınları, National Geographic Dergisi, Mart ayı eki, s: 6. 2007.

[15] Tadic V. M., Dobric S., Markovic G. M., Arsic I. A.,Menkovic N. R.,Stevic T. “Anti-inflammatory, gastroprotective, free-radical-scavenging, and antimicrobial activities of hawthorn berries ethanol extract”Journal of Agricultural and Food Chemistry 56, 7700-7709, 2008.

[16] Wang S.Y, Chai J.Y,, Zhang W.J., Liu X.,Du YCheng Z.Z.,Xiang X."HPLC determination of five polyphenols in rat plasma after intravenous administrating hawthorn leaves extract and its application to pharmacokinetic study”Yakugaku Zasshi, 130, 1603- 1613, 2010.

[17]Refaat A. T.,"Phytochemical and biological activities of Crataegus sinaicagrowing in Egypt, Asian Pacific”Journal of Tropical Medicine, 257-261, 2010. 
[18]Bor Z., Arslan R., Bektaş N., Pırıldar S., Dönmez, A. A., "Remove from marked Records Antinociceptive, antiinflammatory, and antioxidant act. of the ethanol extract of C. orientalis leaves"Turkish Journal of Medical Sciences,42, 315-324, 2012.

[19] Amel B., Seddik K., Shtaywy A., Saliha D., Mussa A. Z., Assia B., Saliha D., Abderahmane B., Smain A., "Phytochemical analysis, antioxidant activity and hypotensive effect of Algerian azarole (Crataegus azarolus L.) leaves extracts"Research Journal of Pharmaceutical, Biologica and Chemica Sciences, 5, 286-305, 2014.

[20]Liu P., Kallio H., Lü D., Zhou C., Yang B., “Quantitative analysis of phenolic compounds in Chinese hawthorn (Crataegus spp.) fruits by HPLC- electrosprayionisation massspectrometry”Food Chemistry 127, 1370- 1377, 2011.

[21] Özyürek M., Bener M., Güçlü K., Dönmez A. A., Süzgeç- Selçuk S, Pırıldar S, Meriçli A.H., Apak R.,"Evaluation of Antioxidant Activity of Crataegus Species Collected from Different Regions of Turkey"Records Natural Products, 6, 263- 277, 2012.

[22] Yılmaz M., Ok T., “Geyik Elması (Malus trilobata C.K. Schneid.)’nın Bazı Biyolojik, Ekolojik ve Etnobotanik Özellikleri”Kahramanmaraş Sütçü İmam Üniversitesi Doğa Bilimler Dergisi, Özel Sayı, 156- 160, 2012.

[23] Tashev A, Petkova, K.."Fruit and seed morphological peculiarities of the critically threatened Eriolobus trilobatus (Rosaceae)"Plant, fungal and habitat diversity investigation and conservation Proceedings of IV BBC, 55- 58, 2006.

[24] Davis P.H. (ed.), "Flora of Turkey and The East Aegean Islands”Edinburg Universty Press, 4, 133-147, 1972.

[25] Cemeroğlu B.,“Gıda Analizleri”Gıda Teknolojisi Derneği Yayınları,480 s, Ankara,2007.

[26] Cemeroğlu B..“Meyve ve Sebze İşleme Endüstrisinde Temel Analiz Metodları”Biltav Yayınları, 381 s,Ankara, 1992.

[27] Düzgüneş O., Kesici T., Kavuncu O. ve Gürbüz F., “Araştırma ve Deneme Metotları”Ankara Üniversitesi Ziraat Fakültesi Yayınları, 229 s,Ankara, 1987.

[28] Riedl H., “Crataegus L., in: Flora Iranica” Edited by Rechinger K. H., Akad. Druck- u. Verlagsanstalt, Graz, 66, 45- 65, 1969.

[29] Anonymous 1: Hue color scale,https://flylib.com/books/en/2.816.1.70/1/ [Son erişim tarihi 20 Aralık 2018]

[30] Türkoğlu N., Kazankaya A.,Şensoy R.İ. "Pomological Characteristics of Hawthorns Species Found in Van Region”Yüzüncü Yıl Üniversitesi Tarım Bilimleri Dergisi, 15, 17-21,2004.

[31] Karadeniz T., Kalkışım Ö., "Edremit ve Gevaş İlçelerinde Yetişen Alıç (Crataegus azarolus L.) Tiplerinin Meyve Özellikleri ve Ümitvar Tiplerin Seçimi”Yüzüncü Yıl Üniversitesi Ziraat Fakültesi Dergisi, 6, $27-33$. 1996.

[32] Çalışkan O., Gündüz K., Bayazıt S., "Sarı Alıç (Crataegus azarolus L.) Genotipinin Morfolojik, Biyolojik ve Meyve Kalite Özelliklerinin İncelenmesi”Gaziosmanpaşa Üniversitesi Ziraat Fakültesi Dergisi, 35, 69-74, 2018.

[33] Balta M. F., Karakaya O., Ekici G. K.,“Çorum’da Yetişen Alıçların (Crataegus spp.) Fiziksel Özellikleri,Ordu Üniversitesi Bilim Teknik Dergisi, 5, 35-41, 2015.

[34] Yavıç A., Taylan A. , Balcı H. , Encu T., "Biochemical and Pomological Characteristics of Hawthorn (Crataegus spp.) Fruits Grown in Şemdinli, Hakkâri”Y Yüzüncü Yıl Üniversitesi Tarım Bilimleri Dergisi, 26, 500-504, 2016. 